CEP 17-08

\title{
Unemployment and Income-Distribution Effects of Economic Growth: A Minimum-Wage Analysis with Optimal Saving
}

Richard A. Brecher and Till Gross

Carleton University

June 2017; revised 14 July 2017

\section{CARLETON ECONOMIC PAPERS}
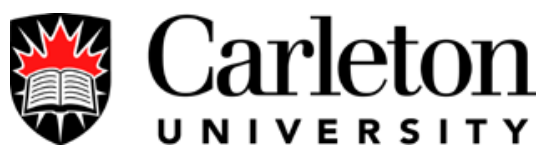

Department of Economics

1125 Colonel By Drive

Ottawa, Ontario, Canada

K1S 5B6 
UNEMPLOYMENT AND INCOME-DISTRIBUTION EFFECTS OF ECONOMIC GROWTH:

A MINIMUM-WAGE ANALYSIS WITH OPTIMAL SAVING

\author{
Richard A. Brecher and Till Gross \\ Department of Economics \\ Carleton University \\ 1125 Colonel By Drive \\ Ottawa ON K1S 5B6
}

June 2017

Revised July 2017

\begin{abstract}
Theoretically and numerically, we analyze the unemployment and income-distribution effects of economic growth, in a model with optimal saving (investment) and a minimum wage for unskilled labor. Within this three-factor model (including skilled labor), an exogenous rise in the growth rate increases unemployment if capital and unskilled labor are complements (versus substitutes), implying a trade-off between (faster) growth and (lower) unemployment. We also show how the growth rate affects the skill premium and factor shares of national income, providing little support for Piketty's (2014) controversial thesis that capital's share is higher when growth is slower.
\end{abstract}

JEL Classification Codes: E24, O41

Key Words: Optimal growth, Minimum wage, Unskilled unemployment, Income distribution

*Email: richard.brecher@ carleton.ca, till.gross@ carleton.ca. Telephone: 613-520-2600, extensions 3765 (Brecher) and 3773 (Gross). We gratefully acknowledge helpful comments and suggestions from Thomas Fischer and workshop participants at Carleton University. 


\section{Introduction}

The specter of a slowdown in economic growth has recently caught the attention of economists and policymakers alike. Possible reasons for such a slowdown are plentiful. For example, Summers (2015) revives the idea of secular stagnation, whereby growth slows because of insufficient demand. On the other hand, Gordon (2012) questions whether productivityenhancing innovations can continue on a scale observed in the past, and he identifies a host of other issues (such as demographics) that may further decrease the growth rate in the United States (and elsewhere). In any case, the potential ramifications of slower growth are wideranging and important. For instance, unemployment may rise, as predicted by Okun's Law, and the distribution of income may become severely skewed, as argued by Piketty (2014).

In light of these concerns, the present paper analyzes how the level of unemployment and the distribution of income respond to changes in the rate of economic growth. To abstract from the underlying determinants of this rate, we specify (and change) it exogenously. Our analysis occurs within a one-good model, under perfect competition and constant returns to scale. This model also includes physical capital arising from optimal savings, as well as fixed endowments of skilled and unskilled labor.

Within our analytic framework, some unskilled labor is unemployed because of a minimum real wage for this particular factor of production. Although minimum wages hold a longstanding place of prominence in the history of economic thought—dating back at least as far as Mill (1848) ${ }^{1}$ — they appear to be scarce in the theoretical literature on optimal growth. This

\footnotetext{
${ }^{1}$ See his critique "Of Popular Remedies for Low Wages" (the title of his chap. XII on pp. 424438 in bk. II of vol. I), as well as Leonard's (2000) section on the "History of Minimum-Wage Legislation and Its Economics".
} 
apparent scarcity might well result from an inherent problem of overdetermination, which is explained (and solved) below.

Although we assume that the minimum wage arises simply from government legislation, one could also interpret it as the result of some other institutional arrangement, such as social custom or labor unions. Alternatively, workers may refuse to accept any job that pays less than some type of unemployment benefit (financed by lump-sum taxes), which could thus be viewed as analytically equivalent to a minimum wage. In any case, within our model, the wage for unskilled labor is constrained to exceed the level required for full employment.

There are two main reasons for assuming a third factor in the form of skilled labor, which remains fully employed because its wage is perfectly flexible. First, it is realistic to recognize that a minimum wage usually applies to only part of the labor force. Second, in an optimally saving economy with exogenous growth and constant returns to scale, a binding minimum wage would overdetermine the steady-state equilibrium if there were only two factors (capital and labor). ${ }^{2}$ Our three-input specification also allows us to consider the implications of factor substitutes versus complements (as defined below), and discover an additional determinant of the wage differential between the two types of labor.

Within our model, an exogenous rise in the rate of growth increases (decreases) the unemployment rate when capital and unskilled labor are complements (substitutes), in the sense that the marginal product of each of these two inputs depends positively (negatively) on the

\footnotetext{
2 The growth rate determines the rate of return on capital (via the household's Euler equation), thereby pinning down the wage rate (in the two-factor case), which thus cannot be fixed also by the minimum wage. For alternative (two-factor) solutions to this overdetermination problem, see Brecher, Chen and Yu (2013) and Brecher and Gross (2017).
} 
quantity of the other input. ${ }^{3}$ In other words, if and only if capital and unskilled labor are complements, there is a trade-off between (faster) growth and (lower) unemployment.

Such a growth-unemployment trade-off has been studied previously under alternative assumptions about the labor market. For example, Aghion and Howitt (1994) and Pissarides (1990, chap. 2; 2000, chap. 3) use search-and-matching models of frictional unemployment, whereas Brecher, Chen and Choudhri (2002) assume that unemployment arises for efficiencywage reasons. The present paper contributes to this literature by analyzing the simpler but classic case of unemployment due to a minimum-wage constraint. This case sheds new light on the relationship between growth and unemployment, by featuring the important role of factor substitutes/complements.

We also address the recent controversy over Piketty's (2014, especially p. 233) thesis that a fall in the rate of growth implies a rise in capital's share of national income. ${ }^{4}$ Although our minimum-wage analysis does not generally support his thesis, some support is provided under certain assumptions about depreciation of capital and elasticities of factor substitution (between capital and both types of labor).

Section 2 sets up our basic model of optimal growth with a minimum wage. Using this model, section 3 explores the relationship between the rates of growth and unemployment. Section 4 analyzes how a change in the growth rate affects the distribution of income among the

\footnotetext{
${ }^{3}$ Although various empirical studies suggest that capital is more complementary with skilled than with unskilled labor (as discussed by Violante, 2008), there appears to be no consensus on whether capital and unskilled labor are in fact complements rather than substitutes (as defined here). We thus consider both of these alternative possibilities.

${ }^{4}$ For a detailed critique of this book and of some related work, see Rognlie (2015). See also Fischer's (2017) critique, within an optimal-growth model without a minimum wage.
} 
three factors of production. To estimate the magnitude of our theoretical results, section 5 numerically simulates the effects of economic growth on unemployment and income distribution. Section 6 provides some concluding remarks.

\section{Basic Model}

The economy produces a single good that can be consumed or added to the capital stock. The production function for this good is concave and linearly homogeneous with positive but diminishing marginal productivity, as follows:

$$
Y=F(K, L, S) \equiv F(K, \lambda l, \lambda s) \equiv \lambda f(k, l, s),
$$

where $Y$ denotes aggregate output; $K$ stands for the total stock of capital; $l$ and $s$ represent the economy's inputs of unskilled and skilled labor, respectively, in natural units; $\lambda$ is the number of efficiency units per natural unit of (skilled and unskilled) labor; while $k \equiv K / \lambda, L \equiv \lambda l$ and $S \equiv \lambda s$. Although all variables (above and below) are functions of time, the time argument $t$ is suppressed for simplicity of notation, except where needed for clarity.

Identical firms maximize profits under perfect competition, thereby satisfying the usual marginal-productivity conditions, which are

$$
\begin{aligned}
& r=f_{k}(k, l, s), \\
& w=f_{l}(k, l, s), \\
& q=\left[f(k, l, s)-k f_{k}(k, l, s)-l f_{l}(k, l, s)\right] / s,
\end{aligned}
$$

where $r$ denotes the real rental rate of capital; $w$ and $q$ represent the real wage rates per efficiency unit of unskilled and skilled labor, respectively; subscripts of functions denote partial derivatives (e.g., $f_{k} \equiv \partial f / \partial k$ and $f_{k k} \equiv \partial f_{k} / \partial k$ ); and the right-hand side of (4) is equivalent to $f_{s}(k, l, s)$ by Euler's Theorem. As explained below, (2) - (4) determine the steady-state values of $k, l$ and 
$q$ - given $w$ (fixed by the minimum wage), $r$ (determined by the growth rate in the Euler equation for dynamic optimization), and $s$ (equalling the perfectly inelastic supply of skilled labor).

For simplicity of exposition, skilled and unskilled labor have fixed endowments, equal to $\bar{s}$ and $\bar{l}$, respectively. Since $q$ is perfectly flexible, skilled labor remains fully employed, with $s=\bar{s}$ at all points in time. However, because $w$ is subject to a binding minimum-wage constraint, $l$ is variable, and unskilled labor has a rate $1-l / \bar{l}$ of unemployment.

Subject to their budget constraint, identical consumers competitively maximize the present discounted value of lifetime utility, in a way consistent with the behavior of a representative household. ${ }^{5}$ In particular, according to the usual specification, this household maximizes

$$
V \equiv \int_{0}^{\infty} e^{-\rho t}\left[C^{1-\theta} /(1-\theta)\right] \mathrm{d} t
$$

subject to

$$
\dot{X}=(r-\delta) X+w \lambda l+q \lambda s-C
$$

where $\theta(\neq 1)$ is a strictly positive constant ${ }^{6}, \rho$ stands for the constant rate of time preference, $C$

\footnotetext{
${ }^{5}$ We could relax this one-household assumption — at the cost of complicating the expositionwithout affecting our theoretical results about steady states. Furthermore, in the numerical simulations of section 5 , the transitional paths between steady-state equilibria remain virtually unchanged for all aggregate variables (such as $\mathrm{k}$ and $l$ ) when the model is extended to include three representative households, each with the same utility function but different factor endowments.

${ }^{6}$ Under this formulation, the instantaneous utility function [namely, $\left.C^{1-\theta} /(1-\theta)\right]$ has an elasticity of marginal utility equal to $\theta$. Alternatively, this elasticity would equal 1 if instantaneous utility were re-specified as $\ln C$, in which case our analysis and results would be qualitatively unchanged. In fact, for this log-utility case, simply replace $\theta$ by 1 in all applicable equations except (5), (8) and (10).
} 
represents total consumption, $X$ denotes aggregate wealth, $\delta(\geq 0)$ is capital's constant rate of depreciation (and hence $r-\delta$ equals the rate of interest on assets), while an overdot indicates a time derivative (e.g., $\dot{X} \equiv d X / d t)$.

The value of $\lambda$ at time $t$ is

$$
\lambda(t)=\lambda(0) \mathrm{e}^{g t}
$$

where $g(\geq 0)$ is the constant rate of labor-augmenting technical progress. With this equation, as well as the definitions that $x \equiv X / \lambda$ and $c \equiv C / \lambda$, the household's optimization problem can be restated as maximizing

$$
V \equiv \lambda(0)^{1-\theta} \int_{0}^{\infty} e^{-[\rho-(1-\theta) g] t}\left[c^{1-\theta} /(1-\theta)\right] \mathrm{d} t
$$

subject to

$$
\dot{x}=(r-\delta-g) x+w l+q s-c,
$$

where $\rho-(1-\theta) g$ is now the household's effective discount rate, assumed to be greater than zero for well-known reasons (as discussed by Barro and Sala-i-Martin ,1995, pp. 73-74).

The current-value Hamiltonian for this maximization problem is

$$
H=c^{1-\theta} /(1-\theta)+\mu[(r-\delta-g) x+w l+q s-c]
$$

where $\lambda(0)=1$ by normalization (without loss of generality); and $\mu$ is a co-state variable that can be interpreted as the shadow price of assets $(x)$. The necessary conditions for a maximum include

$$
\begin{aligned}
& \partial H / \partial c=c^{-\theta}-\mu=0, \\
& \dot{\mu}=[\rho-(1-\theta) g] \mu-\partial H / \partial x=\mu(\rho+\delta+\theta g-r),
\end{aligned}
$$

in addition to the wealth-accumulation constraint (9), as well as the usual initial and transversality conditions. 
Note that $f=w l+r k+q s$ because perfectly competitive firms make zero profits under constant returns to scale, and that $x=k$ since household wealth equals the stock of capital. Thus, (11) allows us to rewrite (9) as

$$
\dot{k}=f(k, l, s)-(\delta+g) k-\mu^{-1 / \theta} .
$$

The next two sections derive some key properties of the steady-state equilibrium, at which $\dot{\mu}=\dot{k}=0$. This equilibrium is saddle-path stable, as appendix A shows by examining the dynamic system corresponding to (12) and (13).

\section{Unemployment and Growth}

This section derives a necessary and sufficient condition for a trade-off between unemployment and growth. In deriving this condition, we compare the steady-state equilibrium levels of unemployment for two different rates of exogenous growth.

In steady state (where $\dot{\mu}=0$ ), the Euler equation (12) can be written as

$$
r=\rho+\delta+\theta g .
$$

Substitute this equation into (2); and in (3), replace $w$ by $\bar{w}$, which is a constant representing the binding minimum wage (per efficiency unit of unskilled labor). ${ }^{7}$ Then, differentiate the resulting two equations totally with respect to $g$, after setting $s=\bar{s}$, and solve simultaneously for

$$
\begin{aligned}
& d k / d g=\theta f_{l l} / \Delta, \\
& d l / d g=-\theta f_{l k} / \Delta,
\end{aligned}
$$

where $\Delta \equiv f_{l l} f_{k k}-f_{l k} f_{k l}$.

\footnotetext{
${ }^{7}$ The minimum wage per natural unit of unskilled labor is thus $\lambda \bar{w}$, which grows at the rate $g$, as required for balanced growth.
} 
To ensure that these expressions for $d k / d g$ and $d l / d g$ exist, so that $k$ and $l$ are (singledvalued) functions of $g$, assume that $\Delta$ is non-zero. Note also that $\Delta$ is non-negative, because it is a second-order principal minor of the Hessian matrix of a concave function $(f)$. Therefore, $\Delta>0 .{ }^{8}$ We also have $f_{l l}<0$, by diminishing marginal productivity. Thus, $d k / d g<0$ unambiguously in (15), while $d l / d g \stackrel{<}{=} \begin{aligned}> & > \\ & >\end{aligned}$ as $\begin{aligned} f_{l k} \\ <\end{aligned}$ in (16). ${ }^{9}$

In other words, we have the following result.

Proposition 1. There is a trade-off between growth and unemployment if and only if capital and unskilled labor are complements.

To understand this result intuitively, first note that the rise in $g$ leads to an increase in $r$, in accordance with (14). As usual, such an increase corresponds to a fall in $k$, given diminishing marginal productivity. This fall is accompanied by a reduction (expansion) in $l$ if capital and unskilled labor are complements (substitutes). The possibility of substitutes is due to the presence of the third factor (skilled labor). Without this factor, the two remaining inputs would necessarily be complements, since the marginal product of capital (unskilled labor) then would depend negatively (positively) on $k / l$.

${ }^{8}$ This condition is satisfied in, for example, the case of a CES production function. Alternatively, $\Delta>0$ if the function $f(k, l, \bar{s})$ is homogeneous in $k$ and $l$, in light of Lancaster (1968, sect. 8.5, pp. 131-133). A special case of this second example is the Cobb-Douglas production function.

${ }^{9}$ By an analogous derivation, for an exogenous increase in $\bar{w}$ at constant $g, d l / d \bar{w}<0$ (and

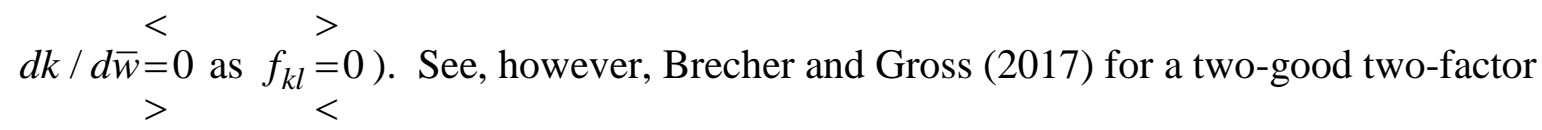
endogenous-growth model in which a minimum-wage hike might paradoxically increase total employment under perfect competition. 


\section{Income Distribution and Growth}

The present section analyzes the steady-state relationship between the rate of growth and the distribution of income. To measure this distribution, we initially examine factor shares of gross national income (including depreciation). Then, the discussion turns to shares of net income (excluding depreciation). Neither of these cases provides general support for Piketty's (2014) thesis about capital's share.

Before proceeding with this analysis, we need to determine how a change in $g$ affects $q$. For this purpose, substitute (2) and (3) into (4) to eliminate $f_{k}$ and $f_{l}$, while replacing $w$ and $s$ by $\bar{w}$ and $\bar{s}$. Then differentiate the resulting equation totally with respect to $g$, using (14). Next, simplify terms by reusing (2) and (3), to verify that

$$
d q / d g=-\theta k / \bar{s} .
$$

Thus, $q$ and $g$ are inversely related. Intuitively, since a rise in $g$ increases $r$ (while leaving $w$ fixed at $\bar{w}), q$ must decrease to prevent profits from falling below zero.

Incidentally, it is interesting to note that (17) implies an inverse relationship between the growth rate and the widely-discussed "skill premium", represented here by $q / \bar{w}$. This relationship suggests another possible determinant of the relative wages of skilled and unskilled labor, thereby providing a contribution to the literature [reviewed by Autor (2014)] on the skill premium and its various causes. Contrary to what might be expected from some of this literature, a rise in the skilled-labor supply $(s)$ within our model would not affect $q / \bar{w}$ in the long run (but would simply raise $k$ and $l$ in the same proportion), since the marginal products of all three factors are homogeneous of degree 0 (in $k, l$ and $s$ ).

\subsection{Gross Shares}

Define $\alpha_{k} \equiv r k /(r k+\bar{w} l+q \bar{s})=1 /(1+w l / r k+q \bar{s} / r k)$, which is capital's 
proportional share of gross national income (before subtracting depreciation). Thus,

$$
d \alpha_{k} / d g=\left[\left(\sigma_{k l}-1\right) l d(\bar{w} / r) / d g+\left(\sigma_{k s}-1\right) \bar{s} d(q / r) / d g\right] \alpha_{k}^{2} / k,
$$

where $\sigma_{k l} \equiv[(\bar{w} / r) /(k / l)] d(k / l) / d(\bar{w} / r)$ and $\sigma_{k s} \equiv[(q / r) /(k / \bar{s})] d(k / \bar{s}) / d(q / r)$, which are the total elasticities of $k / l$ and $k / \bar{s}$ with respect to $\bar{w} / r$ and $q / r$, respectively. Because these input-ratio elasticities let every variable—including output—change with $g$, they can differ from the standard elasticity of technical substitution along a given isoquant.

In examining the right-hand side of (18), note that $d(\bar{w} / r) / d g<0$ by (14), and that $d(q / r) / d g<0$ in accordance with (14) and (17). Thus, $d \alpha_{k} / d g<(>) 0$ if $\sigma_{k l}$ and $\sigma_{k s}$ are both greater (less) than $1 .{ }^{10}$ This condition would be satisfied in (for example) the case of a regular CES production function, whose (constant) elasticity of technical substitution is equal to both $\sigma_{k l}$ and $\sigma_{k s} \cdot{ }^{11}$ On the other hand, $d \alpha_{k} / d g=0$ with a Cobb-Douglas production function, characterized by $\sigma_{k l}=\sigma_{k s}=1$. Moreover, if $\sigma_{k l}-1$ and $\sigma_{k s}-1$ have opposite signs, then $d \alpha_{k} / d g$ is ambiguous in sign.

Similarly,

$$
\begin{aligned}
& d \alpha_{l} / d g=\left[\left(\sigma_{l k}-1\right) k d(r / \bar{w}) / d g+\left(\sigma_{l s}-1\right) \bar{s} d(q / \bar{w}) / d g\right] \alpha_{l}^{2} / l, \\
& d \alpha_{s} / d g=\left[\left(\sigma_{s k}-1\right) k d(r / q) / d g+\left(\sigma_{s l}-1\right) l d(\bar{w} / q) / d g\right] \alpha_{s}^{2} / \bar{s},
\end{aligned}
$$

\footnotetext{
${ }^{10}$ This result generalizes a well-known property of the standard two-factor one-good model, in which a rise in the wage/rental ratio increases (decreases) capital's share if the elasticity of technical substitution is greater (less) than 1 . In the present three-factor model, we must consider two separate elasticities, each between capital and a different type of labor.

${ }^{11}$ From now on, we use the terms "regular CES" and "nested CES" to distinguish between the conventional type of CES production function and the two-level type introduced by Sato (1967).
} 
where $\alpha_{l}$ and $\alpha_{s}$ are the proportional national-income shares of unskilled and skilled labor, respectively, while $\sigma_{l s}\left(=\sigma_{s l}\right)$ is analogous to $\sigma_{k l}\left(=\sigma_{l k}\right)$ and $\sigma_{k s}\left(=\sigma_{s k}\right)$. As these two equations show, $d \alpha_{l} / d g$ and $d \alpha_{s} / d g$ are generally ambiguous in sign, although the latter derivative is positive (negative) if both $\sigma_{s k}$ and $\sigma_{s l}$ are greater (less) than 1.

Nevertheless, the following two points can be made if the production function is of the regular CES type, in which case our input-ratio elasticities are all the same (and equal to the constant elasticity of technical substitution). First, when (17) is substituted into (19), simple rearrangement of terms shows that $d \alpha_{l} / d g=0$. Second, because unskilled labor's share thus remains unchanged while the three factor shares sum identically to $1, d \alpha_{s} / d g=-d \alpha_{k} / d g .{ }^{12}$

Thus, we can now state the following result.

Proposition 2. With regular CES technology, a rise in the growth rate increases (decreases) capital's proportional share of gross national income if the elasticity of technical substitution is less (greater) than 1, has the exact opposite effect on skilled labor's share, and has no effect on the share of unskilled labor.

This constancy of unskilled labor's share does not necessarily survive a relaxation of the regular CES specification, which requires every pair of factors to be complements. For example, suppose instead that capital and labor are substitutes (in the sense that $f_{l k}<0$ ). Then, a rise in $\mathrm{g}$ increases $l / \bar{s}$ (by Proposition 1) while raising $\bar{w} / q$ [by (17)], thereby implying that $\sigma_{l s}<0$. By similar reasoning, $\sigma_{l k}>0$ [(in light of (15) and (16)]. Given the signs of these two

12 The fact that $d \alpha_{k} / d g$ and $d \alpha_{s} / d g$ have opposite signs is easily reconfirmed, by comparing (20) with (18), while noting that $d r / d g>0>d q / d g$ from (14) and (17). 
elasticities, and using (17), we can easily verify that the right-hand side of (19) is strictly positive.

Other common measures of income distribution are the relative (versus proportional) income shares, represented by $\alpha_{k} / \alpha_{l}(=r k / \bar{w} l), \alpha_{k} / \alpha_{s}$ and $\alpha_{s} / \alpha_{l}$. If there were only two factors, each one's relative and proportional shares would clearly have to change in the same direction. However, in the present three-input model, the two types of shares for each factor can instead change in opposite directions.

Proposition 2 immediately implies the following result about relative shares.

Proposition 3. In the case of regular CES technology with an elasticity of technical substitution that is less (greater) than 1, a rise in the growth rate increases (decreases) capital's gross income relative to each type of labor's income, while lowering (raising) skilled relative to unskilled labor's income.

When the regular-CES restriction is relaxed, there are a few additional results about the relationship between the growth rate and relative income shares. First, if we assume that capital and labor are substitutes (in the sense that $f_{l k}<0$ ), then (16) and (17) imply that $d\left(\alpha_{s} / \alpha_{l}\right) / d g<0$. Under the additional assumption that the production function has the nested CES form, it is straightforward (but tedious) to show that $d\left(\alpha_{k} / \alpha_{l}\right) / d g<0$ as well. Alternatively, if $f_{l s}<0$, then $d\left(\alpha_{k} / \alpha_{l}\right) / d g>0$ by a simple proof. ${ }^{13}$

\footnotetext{
${ }^{13}$ Differentiate $\bar{w} l / r k$ with respect to $g$, use (14) - (16), and note that $l f_{l l}+k f_{l k} \equiv-s f_{l s}$ (as implied by Euler's Theorem). Incidentally, this identity confirms that if $f_{l s}<0$, then $f_{l k}>0$ (because $f_{l l}<0$ ).
} 


\subsection{Net Shares}

Since depreciation is substantial in relation to total output, capital's share of gross income significantly overstates this factor's potential contribution to consumption or investment. For this reason, shares of net income (excluding depreciation) are arguably at least as important as gross shares. Moreover, in examining the share of capital, Piketty (2014) focuses on the net (rather than gross) version of this share.

Thus, define $\tilde{\alpha}_{k} \equiv(r-\delta) k /[(r-\delta) k+\bar{w} l+q \bar{s}]$, which is capital's proportional share of net national income. Using this definition and the above one for capital's gross share, straightforward manipulation shows that

$$
\tilde{\alpha}_{k} \equiv 1 /\left[1+\left(1 / \alpha_{k}-1\right) /(1-\delta / r)\right] .
$$

Similarly, the net shares of unskilled and skilled labor can be expressed as follows:

$$
\begin{aligned}
& \tilde{\alpha}_{l} \equiv 1 /\left(1 / \alpha_{l}-\delta k / \bar{w} l\right), \\
& \tilde{\alpha}_{s} \equiv 1 /\left\{1+\left[\alpha_{k}(1-\delta / r)+\alpha_{l}\right] / \alpha_{s}\right\} .
\end{aligned}
$$

Using (21) - (23) and Proposition 2, while noting that $d(k / l) / d g<0$ if skilled and unskilled labor are complements ${ }^{14}$, we immediately obtain the following result. Proposition 4. If the elasticity of technical substitution is less (greater) than 1 in the case of regular CES technology, an increase in the growth rate has a positive (ambiguous) effect on capital's proportional share of net national income, and negative (ambiguous) effects on the net shares of both skilled and unskilled labor.

Since $\tilde{\alpha}_{s} / \tilde{\alpha}_{l}(=q \bar{s} / \bar{w} l)=\alpha_{s} / \alpha_{l}$, Propositions 3 and 4 immediately imply the following result.

\footnotetext{
${ }^{14}$ From (15), (16) and the identity in footnote 13, $d(k / l) / d g=-\bar{s} f_{l s} \theta / \Delta l^{2}<0$.
} 
Proposition 5. For regular CES technology with an elasticity of technical substitution that is less (greater) than 1, an increase in the growth rate has a positive (ambiguous) effect on capital's net income relative to each type of labor's income, while lowering (raising) skilled relative to unskilled labor's income.

\section{Numerical Analysis}

This section conducts numerical simulations to provide rough estimates of the (abovederived) effects of economic growth on unemployment and income distribution. For this purpose, we use a discrete-time version of our model as outlined in Appendix B. In the experiment conducted, the economy starts on a path of balanced growth, and then the (exogenous) rate of (labor-augmenting) technical change falls permanently in period 51. Here we consider a growth-rate decrease (as opposed to the increase discussed in our theoretical sections), since the public/academic debate currently appears to focus on a slowdown in growth (as noted in the introduction).

\subsection{Calibration}

Following Trabandt and Uhlig (2011), we set the intertemporal elasticity of substitution equal to 0.5 (implying that our $\theta=2$ ), the depreciation rate $(\delta)$ to 0.07 , the initial rate of growth to $2 \%$, and each time period to one year. As for our new growth rate, it is arbitrarily specified as $1 \%$. We also set the endowment of unskilled labor $(\bar{l})$ equal to 1 by choice of units, while assuming that the relative supply of skilled labor $(\bar{s} / \bar{l}=\bar{s} / 1)$ is 1.14 , which corresponds to the ratio of labor-force participants with a bachelor's degree or higher to those with high-school or 
less education in the United States population aged 25-64. ${ }^{15}$

Our production function is $f(k, l, s)=\left[a z^{\phi}+(1-a) s^{\phi}\right]^{1 / \phi}$, where $z \equiv\left[b k^{\eta}+(1-b) l^{\eta}\right]^{1 / \eta}$. The variable $z$ can be interpreted as the quantity of a composite input, produced by capital and unskilled labor, for use with skilled labor; while $a, b, \eta$ and $\phi$ are parameters. With this formulation, we consider two distinct scenarios. The first one assumes that $\phi=\eta$, which corresponds to a regular CES function (characterized by $f_{l k}>0$ ). The second scenario adopts a nested CES function with $f_{l k}<0$, implying that $\phi>\eta$.

In the regular CES case, we set the elasticity of technical substitution at 0.67 , corresponding to $\phi=\eta=1-1 / 0.67$. For the nested CES case: $\eta=1-1 / 1.67$, which implies that the elasticity of substitution between capital and unskilled labor is 1.67, in accordance with Krusell, Ohanian, Ríos-Rull and Violante (2000) ${ }^{16}$; while $\phi=1-1 / 0.67$ as before, yielding 0.67 as the substitution elasticity for skilled labor and the composite input (of capital and unskilled labor).

In each case, we calibrate the parameters $a, b$ and $\bar{w}$ to achieve the following outcomes on the initial balanced-growth path: capital's proportional share of gross national income is 0.35 , the skill premium is 1.94 , and the unemployment rate $(1-l / \bar{l}=1-l / 1)$ for unskilled labor is $10 \%{ }^{17}$

15 This calculation uses seasonally adjusted data from the Bureau of Labor Statistics for January 2016. Excluded are workers with less education than a bachelor's degree but more than high school, since the Bureau does not provide earnings data (see below) for this category.

16 They use a different specification of the nested CES function, where capital and skilled (rather than unskilled) labor form the composite input. Their specification, however, does not allow for the present possibility of $f_{l k}<0$. Unlike them, moreover, we do not distinguish between capital equipment and structures.

${ }^{17}$ More specifically: in the regular CES case, $a=0.6873, b=0.8355$ and $\bar{w}=0.52$; while the nested CES case has $a=0.6228, b=0.4922$ and $\bar{w}=0.3573$. 
Although our unemployment rate may seem to be on the high side—according to the (U.S.) Bureau of Labor Statistics, the average rate in January 2016 for people with a high-school degree or less was only $5.7 \%$ - the low participation rate of this group (55.4\%) presumably masks a higher effective rate of unemployment. Moreover, if the unemployment rate were initially 5.7\% in the regular CES case, the minimum wage would cease to bind along the new balanced-growth path and unemployment would completely disappear, thereby drastically strengthening the growth-unemployment trade-off reported below. The skill premium corresponds to the ratio of median weekly earnings of people with a bachelor's degree or more education to those with a high-school degree or less, in the data set indicated above. The specified value of capital's share is standard in the literature. We also choose the household's time-discount factor ( $\beta$ from Appendix B) so that the annual interest rate net of depreciation and growth $(r-\delta-g)$ along the initial balanced-growth path is $4 \% .^{18}$

\subsection{Trade-off between Unemployment and Growth}

For the case in which capital and unskilled labor are complements, our estimates show a clear trade-off between unemployment and growth, consistent with Proposition 1. As Figure 1 illustrates for regular CES technology (and hence for $f_{l k}>0$ ), a drop in the growth rate (from $2 \%$ to $1 \%$ after $t=50)$ causes the steady-state rate of unemployment $(1-l$ given $\bar{l}=1)$ to decrease dramatically (from $10 \%$ to $2.2 \%$ ).

\footnotetext{
${ }^{18}$ This choice ensures that $\beta<1$, which is usually assumed in the literature with infinitely-lived dynasties. In the discussion of robustness (below), we also consider the case where $r-\delta=0.04$ and $\beta>1$, as assumed by Trabandt and Uhlig (2011). Under these alternative assumptions, our results are even stronger.
} 


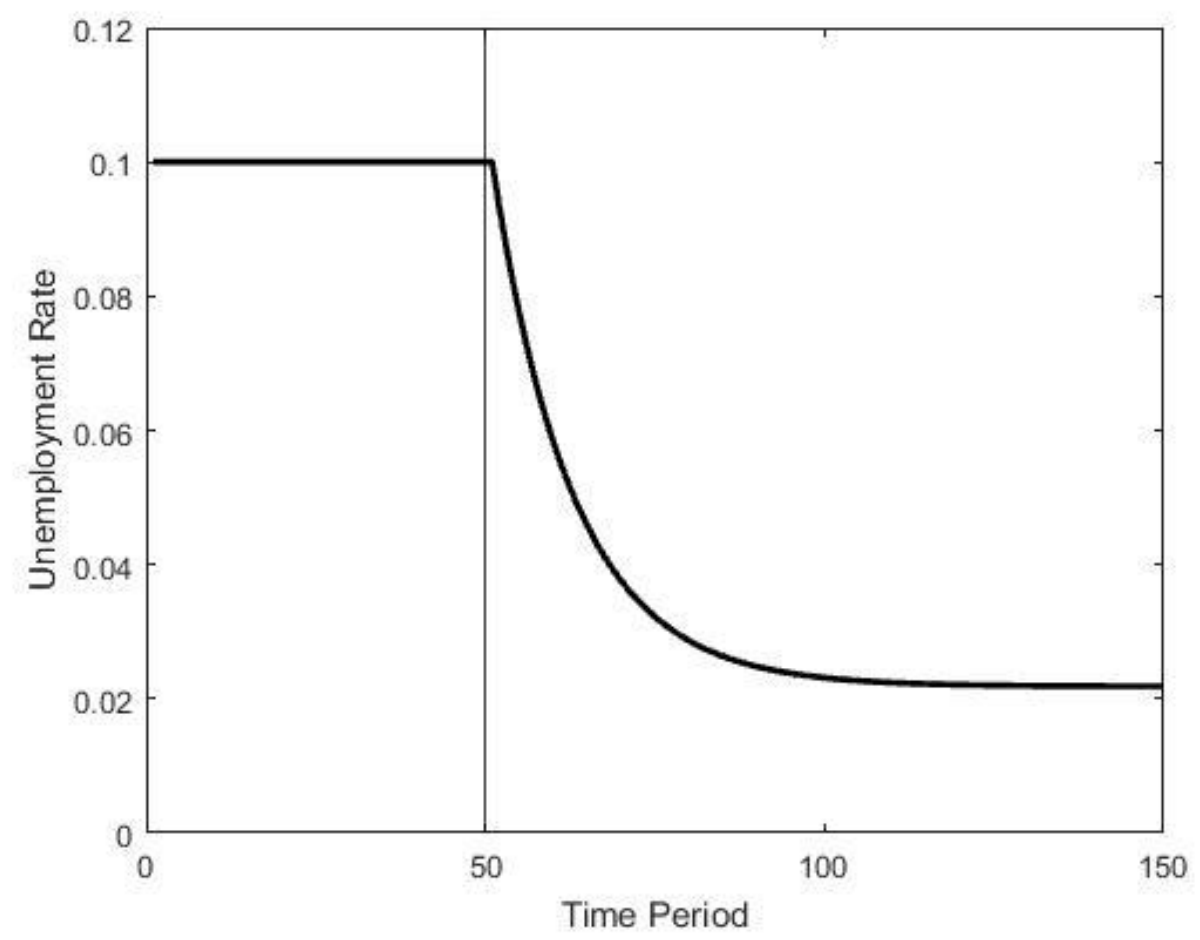

Figure 1: Unemployment Over Time with Regular CES Technology

Notably, despite this strong labor-market improvement, the slowdown in growth reduces lifetime utility $(V)$ of the representative household. This result continues to hold for a wide range of reasonable (and even unreasonable) parameter choices. At the same time, moreover, the skill premium $(q / \bar{w})$ rises substantially (by $13.3 \%)$.

When capital and unskilled labor are instead substitutes (with $f_{l k}<0$ ), a drop in the growth rate then increases unemployment. In our parametrization of the nested CES case, the unemployment increase is relatively small (from $10 \%$ to $12.6 \%$ ). It is thus unsurprising that a slowdown in growth again reduces the lifetime value of household utility. The corresponding rise $(13.7 \%)$ in the skill premium is comparable to the rise in the previous (regular-CES) case. 


\subsection{Evolution of Factor Shares}

In accordance with the theoretical analysis (above) and as illustrated by Figure 2 for the regular CES case, the proportional share of unskilled labor in gross income remains constant (at 19\%), while skilled labor's share increases (from $46 \%$ to $48 \%$ ) and capital's decreases (from $35 \%$ to $33 \%$ ). The movement in proportional shares of net income is more pronounced in Figure 3, where the share of capital still drops (now from $20 \%$ to $15 \%$ ), while unskilled labor's share rises modestly (from $23 \%$ to $24 \%$ ) and skilled labor's again increases (from $57 \%$ to $61 \%$ ). ${ }^{19}$

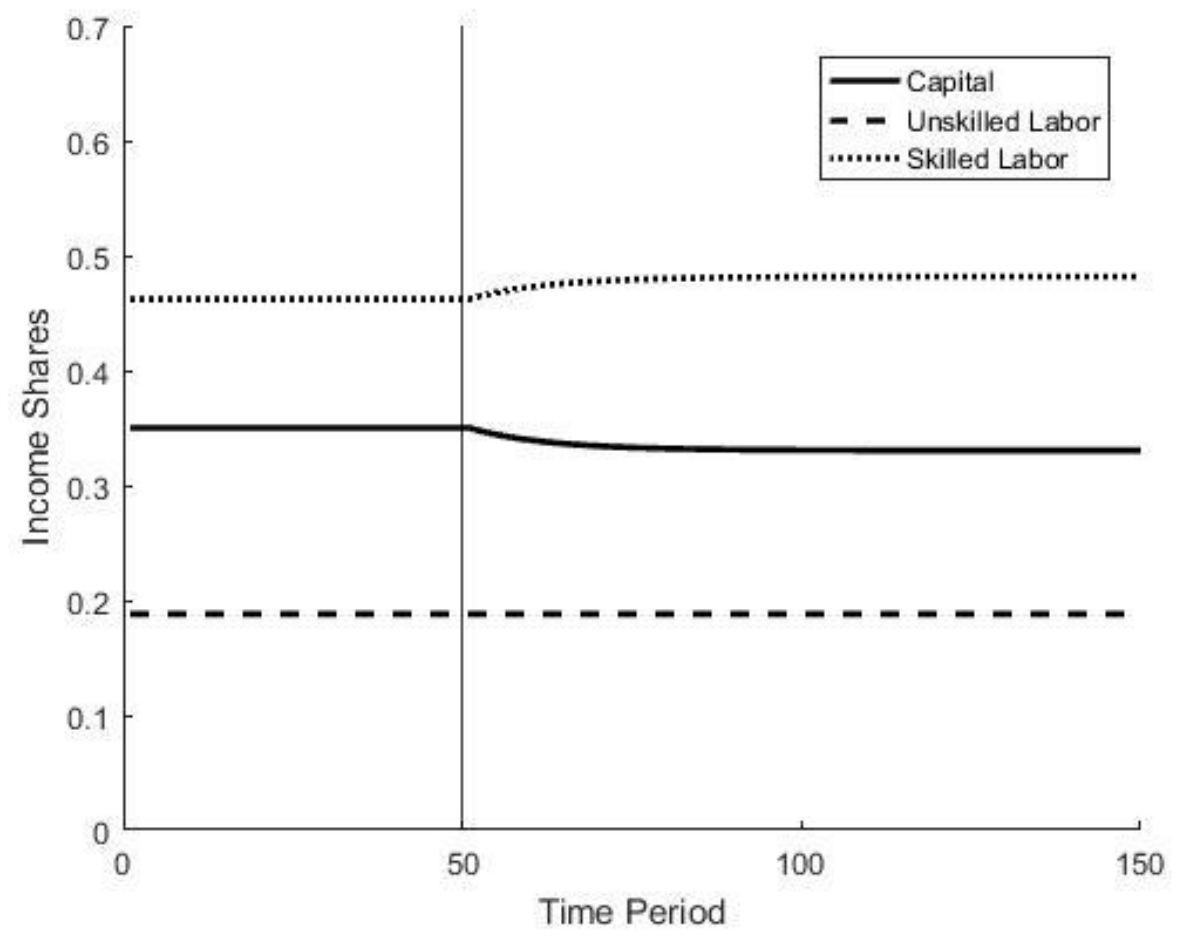

Figure 2: Proportional Shares of Gross Income Over Time with Regular CES Technology

${ }^{19}$ Capital's gross (net) income relative to the income of unskilled labor drops from 1.86 to 1.76 (0.86 to 0.63$)$, the corresponding drop for capital relative to skilled labor is from 0.76 to 0.69 (0.35 to 0.25$)$, and skilled relative to unskilled labor's income rises from 2.46 to 2.56 . 


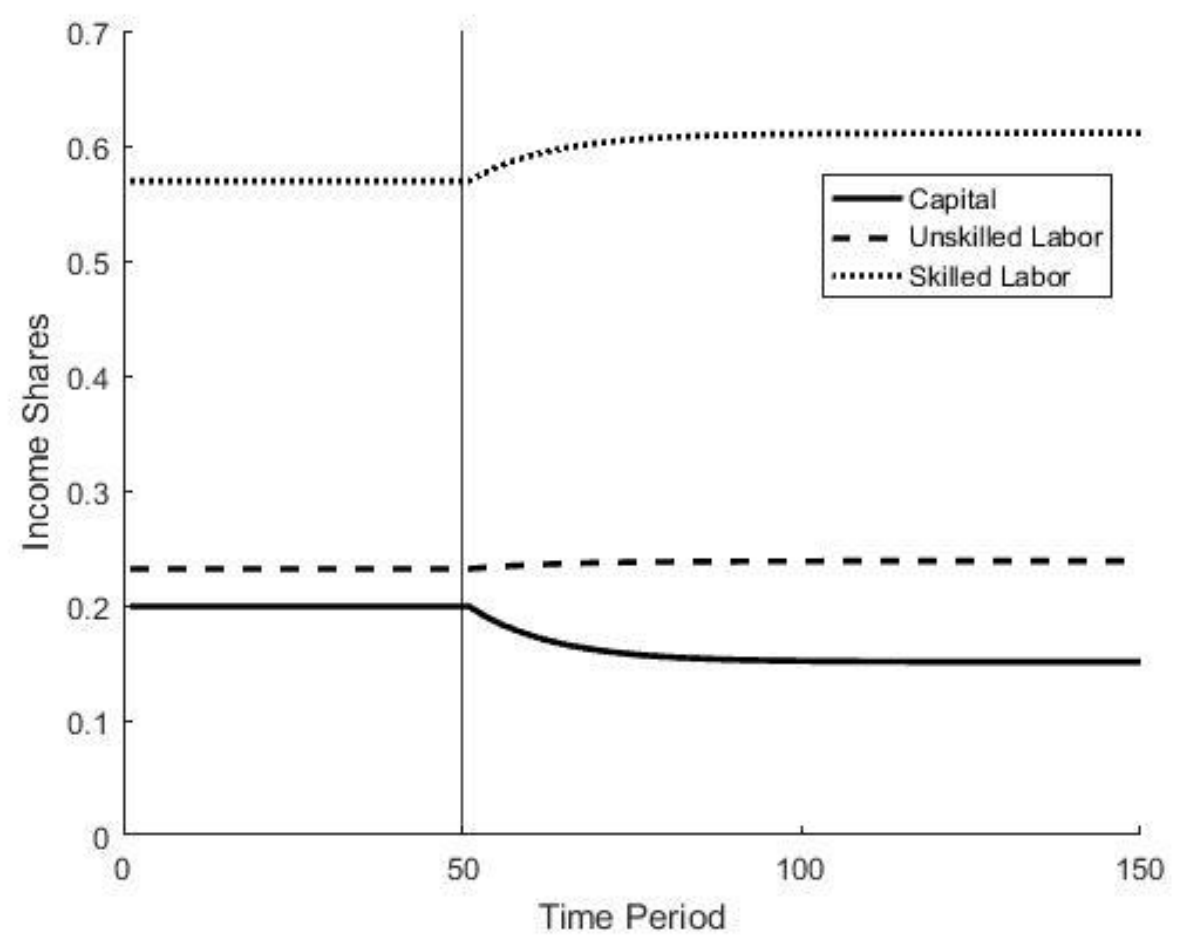

Figure 3: Proportional Shares of Net Income Over Time with Regular CES Technology

Whereas these numerical results accord with our Propositions 2 and 4, they contradict Piketty's (2014) thesis that a fall in the growth rate will raise the share of capital. The driving force for this contradiction is our (conventional) adoption of a less-than-unitary elasticity of technical substitution. Larger values of this elasticity, however, are considered in the robustness exercises below.

For the nested CES case illustrated in Figure 4, capital's proportional share of gross income remains almost unchanged (at approximately 35\%), while unskilled labor's share declines (from $19 \%$ to $17 \%$ ) and skilled labor's grows (from $46 \%$ to $48 \%$ ). In terms of net income shares, Figure 5 shows a substantial reduction for capital (from $20 \%$ to $16 \%$ ), along with a decrease for 
unskilled labor (23\% to $22 \%$ ) and an increase for skilled labor (57\% to $62 \%){ }^{20}$ Thus, once again contrary to Piketty's (2014) thesis, the share of capital fails to rise in response to slower growth.

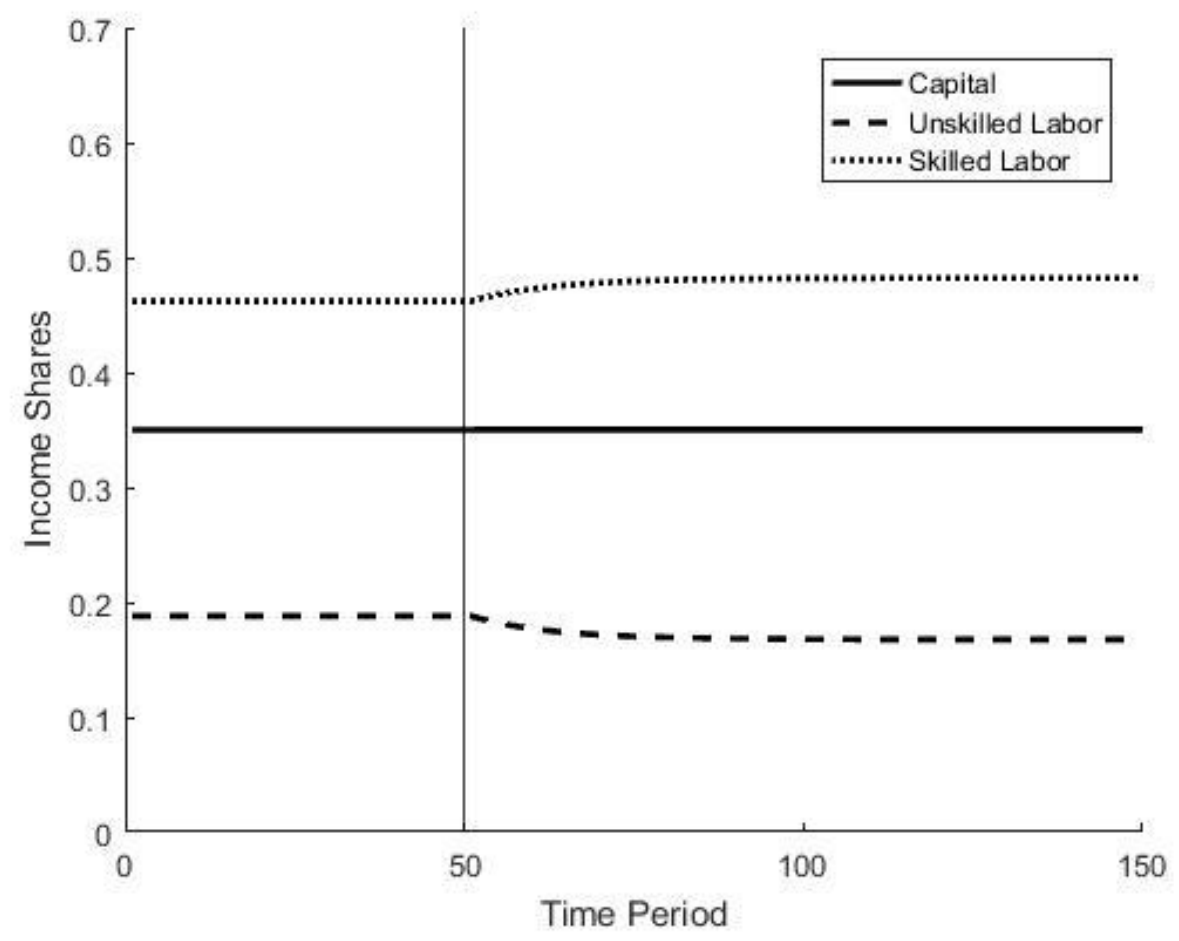

Figure 4: Proportional Shares of Gross Income Over Time with Nested CES Technology

${ }^{20}$ Capital's gross (net) income relative to the income of unskilled labor now drops from 1.86 to 2.09 (0.86 to 0.75$)$, the corresponding drop for capital relative to skilled labor is from 0.76 to 0.73 (0.35 to 0.26$)$, while skilled relative to unskilled labor's income rises from 2.46 to 2.88 . 


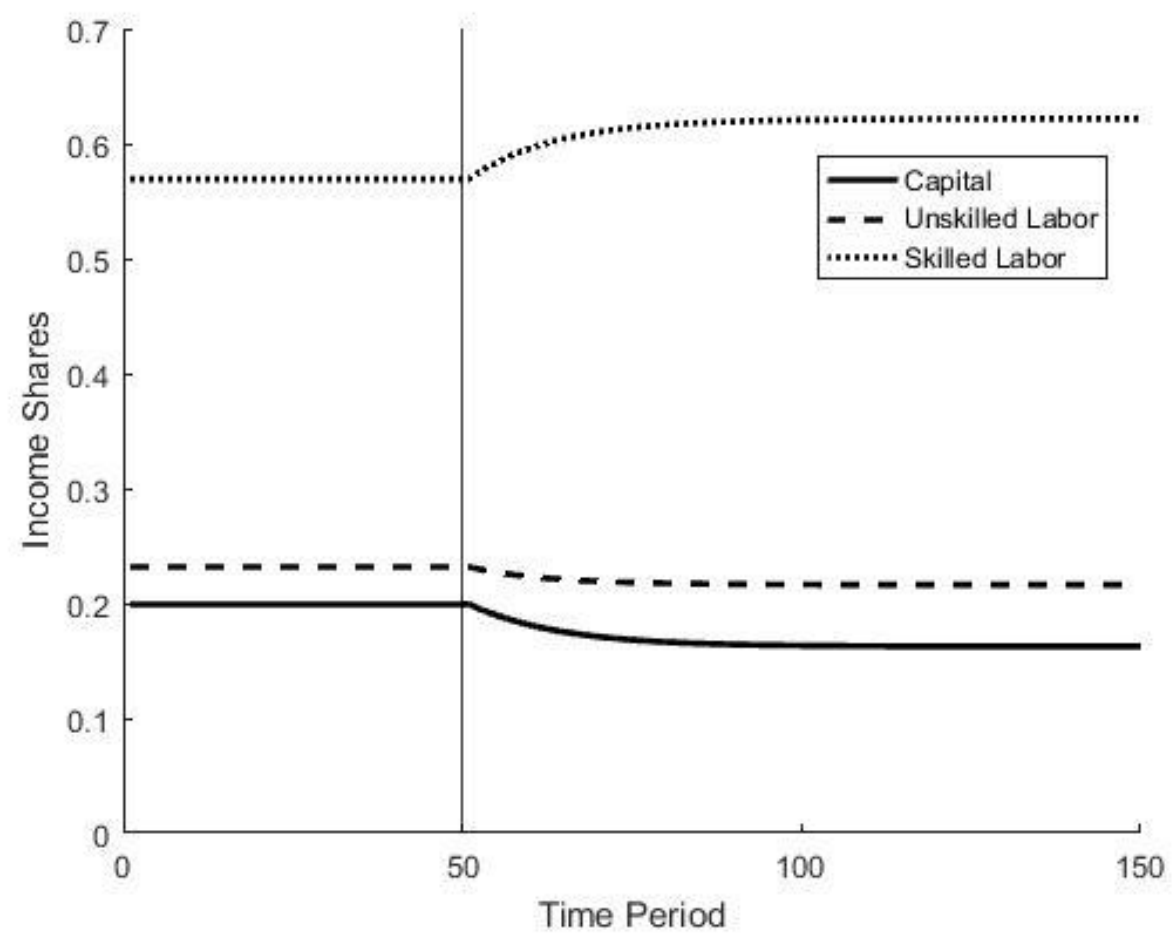

Figure 5: Proportional Shares of Net Income Over Time with Nested CES Technology

\subsection{Robustness}

This section investigates the robustness of our numerical results in three different ways. First, we consider the implications of changes in two key elasticities that the literature does not tightly pin down. In each case, when an elasticity is changed, other parameters are recalibrated to achieve the same targeted outcomes (e.g., initial values of the unemployment rate and skill premium) specified above. Second, we examine the consequences of an alternative assumption about the rate of interest. The third exercise is to explore the effects of relaxing the onehousehold assumption. Taken together, these three exercises confirm the robustness of our simulations.

Perhaps the most important finding relates to the elasticity of technical substitution in the case of regular CES technology. More specifically, unless this elasticity is almost 2 or greater, a drop in the growth rate still lowers capital's proportional net-income share (the type of capital 
share examined by Picketty, 2014). This threshold value, moreover, lies well above widely cited estimates. $^{21}$

When we increase or decrease the intertemporal elasticity of substitution (IES), all responses to a change in the growth rate are respectively muted or magnified, because of how the IES $(=1 / \theta)$ enters the Euler equation [(14) above or (B9) in appendix B]. In this regard, note that our baseline value of 0.5 for the IES is larger than Havranek's (2015) point estimate of 0.33, but is still well within the range that he finds to be empirically relevant.

If we follow Trabandt and Uhlig (2011) in setting $r-\delta=0.04$ (implying $\beta=1.0004$ ), the unemployment rate's response to a change in the growth rate becomes even more pronounced, especially in the nested CES case. In either CES case (nested or regular), a decrease in the growth rate then leads to a greater decline in capital's proportional share of (gross and net) income, and to a larger rise in the skill premium.

To relax the single-household assumption, imagine instead that there are three (optimally saving) households. Suppose that one of these representative agents earns income from capital only, another has the entire endowment of unskilled labor, and the third supplies all of the skilled labor. As long as all three households have the same utility function (and hence the same Euler equation), the steady-state relationships between the growth rate and national aggregates (such as $k$ and $l$ ) remain the same as before. Even the transitional paths of these aggregates are virtually unchanged in our numerical simulations. Furthermore, in response to a decrease in the growth rate, the time paths of income shares for the three households (capital-only, unskilled and skilled)

${ }^{21}$ Most of these estimates are less than 1 in the empirical literature surveyed by Chirinko (2008). However, some doubts about the validity of this consensus are raised by Palivos (2008) as well as Piketty and Zucman (2015, section 15.5.3). 
are qualitatively the same as — but less pronounced than — the above-illustrated paths for the three factors (capital, unskilled labor, and skilled labor, respectively). ${ }^{22}$ This growth-rate reduction also lowers lifetime utility of every household — regardless of what happens to factor incomesfor the broad range of parameter values considered.

\section{Conclusion}

Motivated by the specter of a slowdown in economic growth, this paper analyzes the effects that the growth rate has on unemployment and income distribution. Our model assumes optimal saving and investment, as well as a minimum wage applied only to unskilled (versus skilled) labor.

Within this three-factor model, an exogenous rise in the growth rate leads to an increase or decrease in unemployment if capital and unskilled labor are respectively complements or substitutes, while skilled (flexible-wage) labor remains fully employed. Thus, complementarity of this type is a necessary and sufficient condition for a trade-off between growth and unemployment.

In the special case of regular CES technology with an elasticity of substitution that is less (greater) than 1, the rise in the growth rate also causes an increase (decrease) in capital's proportional share of gross national income and has the opposite effect on the share of skilled labor, while unskilled labor's share remains unchanged. Qualitatively similar results hold for shares in net income when the substitution elasticity is less than 1, except that unskilled labor's share now falls in response to faster growth. Thus, except under special assumptions about

\footnotetext{
22 This result holds under a wide range of assumptions about the initial distribution of wealth. In our baseline specification, the capital-only, unskilled and skilled households respectively own $50 \%, 10 \%$ and $40 \%$ of the initial wealth.
} 
technology, the present analysis does not provide support for Piketty's (2014) thesis, which predicts an inverse relationship between the growth rate and capital's share.

To estimate the unemployment and income-distribution responses to a decrease in the rate of economic growth, we undertake numerical simulations, using a discrete-time version of our main (continuous-time) model. As these simulations suggest, the effects of growth can be substantial, for a wide range of parameter values. 


\section{Appendix A: Saddle-Path Stability}

We now show that the steady-state equilibrium is saddle-path stable. For this purpose, consider Figure A, which is the phase diagram for the dynamic system described by (12) and (13).

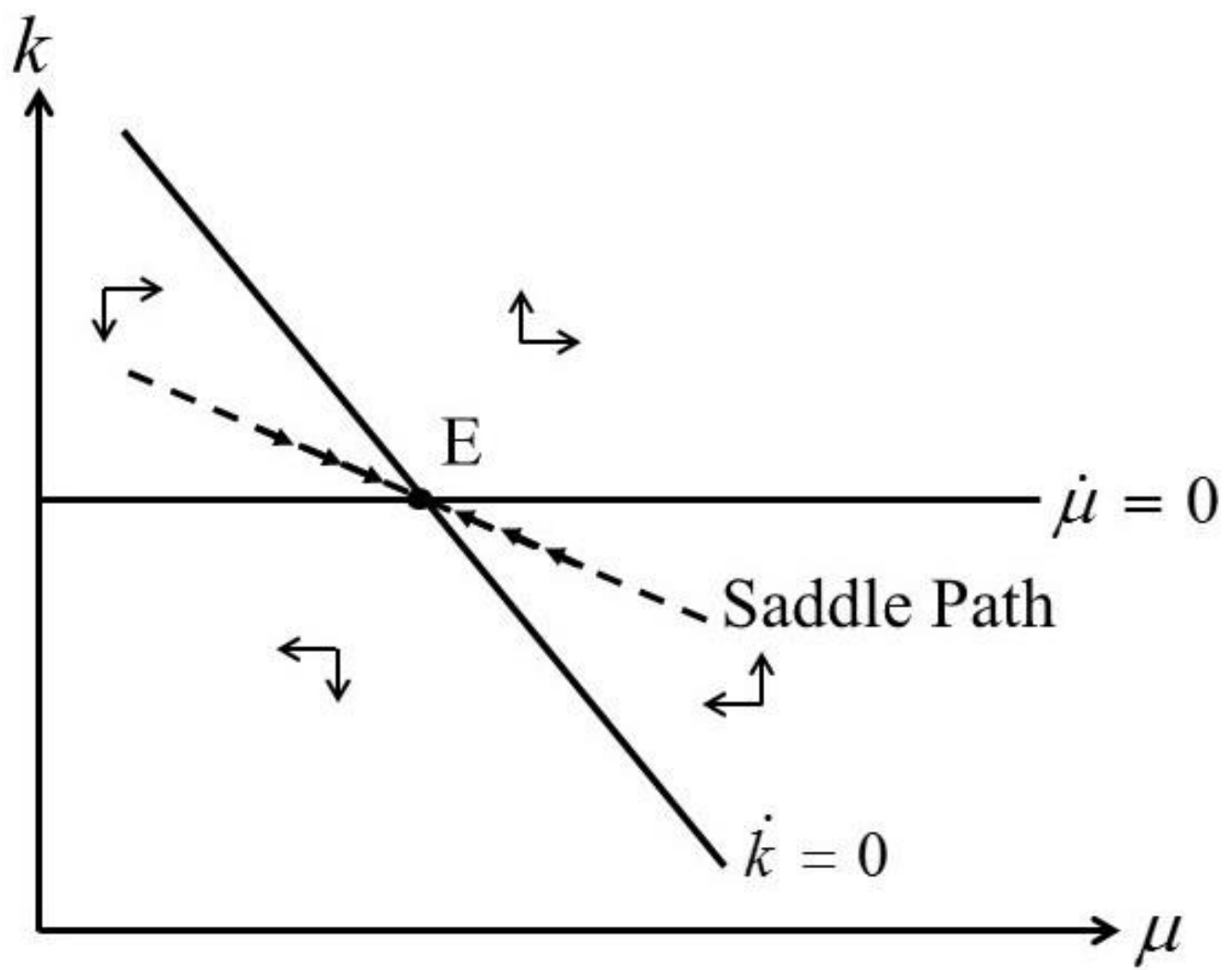

Figure A: Phase Diagram

By the following argument, the schedule for $\dot{\mu}=0$ is a horizontal line, at a height determined by the unique value of $k$ in steady-state equilibrium. Dividing (16) by (15) yields

$$
d l / d k=-f_{l k} / f_{l l}
$$

Similarly, using (15) while noting that $d r / d g=\theta$ from (14), obtain

$$
d r / d k=\Delta / f_{l l}<0,
$$


where the inequality follows from the above assumptions that $\Delta>0>f_{l l}$. Thus, there is only one value of $k$ that satisfies steady-state condition (14) for a given $g$.

Starting from any point on the schedule for $\dot{\mu}=0$, a rise (fall) in $k$ would lower (raise) $r$ by (A2), and hence lead to $\dot{\mu}>(<) 0$ by (12). Thus, at all points above (below) this line, the horizontal arrows of motion for $\mu$ point to the right (left).

Setting $\dot{k}=0$ while holding $g$ and $s(=\bar{s})$ fixed, differentiate (13) totally with respect to $k$. Then use (A1) and (2) to show that

$$
d \mu / d k=\left[\left(f_{l} f_{l k} / f_{l l}\right)+\delta+g-r\right] \theta \mu^{1+1 / \theta} .
$$

To sign this expression, suppose initially that $f_{l k}>0$. Also note that $r>g$ in steady-state equilibrium, to satisfy the transversality condition, as explained by Barro and Sala-i-Martin (1995, p. 71). Then, at this equilibrium point $\mathrm{E}$, the right-hand side of (A3) is negative, in which case the (generally non-linear) curve for $\dot{k}=0$ is negatively sloped. Although this curve could be positively sloped outside the neighborhood of point E, our analysis below would be qualitatively unaffected by this possibility.

In accordance with (13), $\partial \dot{k} / \partial \mu<0$. Thus, at any point to the right or left of the schedule for $\dot{k}=0$, the vertical arrows of motion for $k$ point upward or downward, respectively. The saddle path is the dashed (and generally non-linear) curve. At time $0, \mu$ jumps instantaneously to reach this curve. The economy then moves continuously along the saddle path toward the steady-state equilibrium, located at the point $(\mathrm{E})$ where the three curves intersect.

Alternatively, if $f_{l k}<0$, the right-hand side of (A3) might be positive at the steady-state equilibrium, in which case the schedule for $\dot{k}=0$ would slope upwards at point E. Nevertheless, 
this equilibrium would still be saddle-path stable, as could be readily verified by the same reasoning used above.

\section{Appendix B: Discrete-Time Model}

The household maximizes

$$
V_{0}=\sum_{t=0}^{\infty} \beta^{t} C_{t}^{1-\theta} /(1-\theta)
$$

subject to

$$
X_{t+1}-X_{t}=\left(r_{t}-\delta\right) X_{t}+\bar{w} \lambda_{t} l_{t}+q_{t} \lambda_{t} \bar{s}-C_{t},
$$

where $\beta$, a non-negative constant, is the subjective discount factor between any two contiguous periods; and all other symbols are as defined in the continuous-time model above, except that a time subscript is now used to denote a variable's value in period $t$ (or $t+1)$. Since $c_{t} \equiv C_{t} / \lambda_{t}$, $x_{t} \equiv X_{t} / \lambda_{t}$ and $\lambda_{t+1}=(1+g) \lambda_{t}$ now that $g$ is the growth rate per period, the household's optimization problem can be restated as maximizing

$$
V_{0}=\lambda_{0}^{1-\theta} \sum_{t=0}^{\infty}\left[\beta(1+g)^{1-\theta}\right]^{t} c_{t}^{1-\theta} /(1-\theta)
$$

subject to

$$
x_{t+1}-x_{t}=\left[\left(r_{t}-g-\delta\right) x_{t}+\bar{w} l_{t}+q_{t} \bar{s}-c_{t}\right] /(1+g),
$$

where the effective discount factor is now $\beta(1+g)^{1-\theta}<1$, in accordance with Stokey, Lucas and Presott (1989, section 5.4).

The Lagrangian for this maximization problem can be written as

$$
\mathcal{L}=\sum_{t=0}^{\infty}\left[\beta(1+g)^{1-\theta}\right]^{t} c_{t}^{1-\theta} /(1-\theta)+m_{t}\left[\left(1+r_{t}-\delta\right) x_{t}+\bar{w} l_{t}+q_{t} \bar{s}-c_{t}-(1+g) x_{t+1}\right]
$$

where $m_{t}$ is a Lagrange multiplier, and $\lambda_{0}=1$ without loss of generality. The first-order 
conditions for a maximum include $\partial \mathcal{L} / \partial c_{t}=0$ and $\partial \mathcal{L} / \partial x_{t+1}=0$, which respectively imply the following two equations for all $t \geq 0$ :

$$
\begin{aligned}
& m_{t}=\left[\beta(1+g)^{1-\theta}\right]^{t} c_{t}^{-\theta}, \\
& m_{t}(1+g)=m_{t+1}\left(1+r_{t+1}-\delta\right) .
\end{aligned}
$$

Combining these two equations, we obtain

$$
c_{t}^{-\theta}=\beta(1+g)^{-\theta} c_{t+1}^{-\theta}\left(1+r_{t+1}-\delta\right),
$$

which is the familiar condition for intertemporal optimality.

In steady-state equilibrium (with $c_{t}=c_{t+1}, r_{t}=r_{t+1}$, etc.), (B8) and the usual marginal-

productivity conditions imply

$$
\begin{aligned}
& r^{*}=\beta^{-1}(1+g)^{\theta}+\delta-1, \\
& r^{*}=f_{k}\left(k^{*}, l^{*}, \bar{s}\right), \\
& \bar{w}=f_{l}\left(k^{*}, l^{*}, \bar{s}\right),
\end{aligned}
$$

where asterisks indicate the (unchanging) values of variables in such an equilibrium. These three equations allow us to compute $r^{*}, k^{*}$ and $l^{*}$. Then, $q^{*}=f_{s}\left(k^{*}, l^{*}, \bar{s}\right)$; and $c^{*}=\left(r^{*}-\delta-g\right) k^{*}+\bar{w} l^{*}+q^{*} \bar{s}$ from (B4), since $x^{*}=k^{*}$. Thus, for a given rate of growth, the steady-state equilibrium is independent of the initial stock of wealth (capital).

When we change the growth rate, the initial capital stock $\left(k_{0}\right)$ is given, and the transition path to the new steady state is determined (for $t \geq 0$ ) by the following three equations in three unknowns $\left(c_{t}, l_{t}\right.$ and $\left.k_{t+1}\right)$ :

$$
\begin{aligned}
& \bar{w}=f_{l}\left(k_{t}, l_{t}, \bar{s}\right) \\
& {\left[1+f_{k}\left(k_{t}, l_{t}, \bar{s}\right)-\delta\right] k_{t}+\bar{w} l_{t}+f_{s}\left(k_{t}, l_{t}, \bar{s}\right) \bar{s}=c_{t}+(1+g) k_{t+1}}
\end{aligned}
$$




$$
c_{t}^{-\theta}=\beta(1+g)^{-\theta} c_{t+1}^{-\theta}\left[1+f_{k}\left(k_{t+1}, l_{t+1}, \bar{s}\right)-\delta\right] .
$$

Note that (B13) and (B14) are simply restatements of (B4) and (B5), respectively, after we use marginal-productivity conditions (for capital and skilled labor) and the fact that capital is wealth. 


\section{References}

Aghion, Philippe and Peter Howitt, "Growth and Unemployment", 1994, Review of Economic Studies, 61 (3), July, 477-494.

Autor, David H., 2014, "Skills, Education, and the Rise of Earnings Inequality among the 'Other 99 Percent"”, Science, 344, May 23, 843-851.

Barro, Robert J. and Xavier Sala-i-Martin, 1995, Economic Growth, McGraw-Hill, New York, NY.

Brecher, Richard A., Zhiqi Chen and Ehsan U. Choudhri, 2002, "Unemployment and Growth in the Long Run: An Efficiency-Wage Model with Optimal Savings", International Economic Review, 43 (3), August, 875-894.

Brecher, Richard A., Zhiqi Chen and Zhihao Yu, 2013, “The Trouble with Offshoring: Static and Dynamic Losses in the Presence of Unemployment”, The World Economy, 36 (1), January, pp. 1-11.

Brecher, Richard A. and Till Gross, 2017, “A Minimum-Wage Model of Unemployment and Growth: The Case of a Backward-Bending Demand Curve for Labor", revised May; forthcoming in International Journal of Economic Theory.

Chirinko, Robert S., 2008. “ $\sigma$ : The Long and Short of It”, Journal of Macroeconomics, 30 (2), June, 671-686.

Fischer, Thomas, 2017, “Thomas Piketty and the Rate of Time Preference”, Journal of Economic Dynamics and Control, 77, April, 111-133.

Gordon, Robert J., 2012, “Is U.S. Economic Growth Over?: Faltering Innovation Confronts the Six Headwinds”, Working Paper 18315, August, National Bureau of Economic Research, Cambridge, MA. 
Havránek, Tomáš, 2015, “Measuring Intertemporal Substitution: The Importance of Method Choices and Selective Reporting", Journal of the European Economic Association, 13 (6), December, 1180-1204.

Krusell, Per, Lee E. Ohanian, José Víctor Ríos-Rull and Giovanni L. Violante, 2000, “CapitalSkill Complementarity and Inequality: A Macroeconomic Analysis”, Econometrica, 68 (5), September, 1029-1053.

Lancaster, Kelvin, 1968, Mathematical Economics, The Macmillan Company, New York, NY. Leonard, Thomas C., 2000, “The Very Idea of Applying Economics: The Modern MinimumWage Controversy and its Antecedents", History of Political Economy, 32 (Supplement 1), $117-144$.

Mill, John Stuart, 1848, Principles of Political Economy with some of their Applications to Social Philosophy, John W. Parker, London, UK.

Palivos, Theodore, 2008, "Comment on ' $\sigma$ : The Long and Short of It"”, Journal of Macroeconomics, 30 (2), June, 687-690.

Piketty, Thomas, 2014, Capital in the Twenty-First Century (translated by Arthur Goldhammer), Belknap Press of Harvard University Press, Cambridge, MA.

Piketty, Thomas and Gabriel Zucman, 2015, "Wealth and Inheritance in the Long Run”, in Anthony Atkinson and Francois Bourguignon (eds.), Handbook of Income Distribution, Vol. 2B, Elsevier B.V., Amsterdam, The Netherlands, 1303-1368.

Pissarides, Christopher A., 1990, Equilibrium Unemployment Theory, Basil Blackwell Ltd., Oxford, UK; and second edition, 2000, MIT Press, Cambridge, MA.

Rognlie, Matthew, 2015, "Deciphering the Fall and Rise in the Net Capital Share: Accumulation or Scarcity?", Brookings Papers on Economic Activity, 46 (1), Spring, 1-69. 
Sato, K., 1967, “A Two-Level Constant-Elasticity-of-Substitution Production Function”, Review of Economic Studies, 34 (2), April, 201-218.

Summers, Lawrence H., 2015. "Demand Side Secular Stagnation", American Economic Review, 105 (5), May, 60-65.

Stokey, Nancy L. and Robert E. Lucas, Jr., with Edward C. Prescott, 1989, Recursive Methods in Economic Dynamics, Harvard University Press, Cambridge, MA.

Trabandt, Mathias and Harald Uhlig, 2011, "The Laffer Curve Revisited”, Journal of Monetary Economics, 58 (4), May, 305-327.

Violante, Giovanni L., 2008, “Skill-Biased Technical Change”, in Steven N. Durlauf and Lawrence E. Blume (eds.), The New Palgrave Dictionary of Economics, second edition, Palgrave Macmillan, New York, NY, 520-523. 